\title{
Intermittently Associated Mobile Cognitive Radio Networks using Portability Assisted Routing
}

\author{
Karthik. B, Meena Kumari. G, Jasmin. M, Arulselvi. S.
}

\begin{abstract}
In versatile specially appointed intellectual radio systems, with accessible range groups for optional clients may or may not exist incidentally, because of the dynamism of the essential client exercises. Customary CRN steering calculations, which normally overlook the discontinuous availability of system topology, and customary portability helped directing calculations, which for the most part disregard the range accessibility, are clearly unacceptable. To handle this test, aAssisted Mobility Routing calculation with Spectrum Awareness (MARSA)is proposed to choose transfers in light of not just the likelihood that a hub meets the goal additionally the possibility that exists no less than one accessible channel. This dissertation is proposed to bring the possibility of versatility helped steering to manage the irregularly associated characteristic of versatile impromptu CRNs, and the first to improve the portability helped directing by considering the worldly, spatial, and range spaces in the meantime. Our reenactment comes about show the predominance of MARSA over customary calculations in discontinuously associated portable CRNs.
\end{abstract}

Keywords :Cognitive Radio,Portability, Routing..

\section{INTRODUCTION}

These days, psychological radio systems administration (CRN) has gotten a considerable measure of consideration since it bears the guarantee of lightening the range shortage issue This paper, consist of amobile impromptu CRN, when two hubs can trade their information as it were when they enter each other's transmission path and there exists no less than one accessible channel between them. This is named an Intermittently Connected Mobile CRN (ICMCRN), that ordinarily don"t have incidentally table ways among accessible range. In ICMCRNs, conventional CRN steering conventions are definitely not proper in light of the fact that they normally expect so as to accessible time exercises over essential groups time expected to experience a round of interchanges. Notwithstanding, this presumption does not generally remain constant particularly when the essential clients' usage of the authorized spectrum is high.

Revised Manuscript Received on August 22, 2019.

Karthik.B Assistant Professor, Department of Electronics And Communication Engineering,, Bharath Institute of Higher Education and Research, Chennai, India karthikguru33@gmail.com

MeenaKumari.G Assistant Professor, Department of Electronics And Communication Engineering,, Bharath Institute of Higher Education and Research, Chennai, India meensg85@gmail.com

Jasmin.M, Assistant Professor, Department of Electronics And Communication Engineering,, Bharath Institute of Higher Education and Research, Chennai, India rifriz@gmail.com

Arulselvi.S Assistant Professor, Department of Electronics And Communication Engineering,, Bharath Institute of Higher Education and Research, Chennai, Indiaarulselvi2003@gmail.com
Truth be told, if the sit without moving and occupied lengths of the authorized range are exchanged often inside a brief span, the range is difficult to utilize despite the fact that the usage is low. This is since before utilizing the authorized range for information correspondences, auxiliary clients must intellect the channel and check with others for conceivable range distribution. In this way if the season of these procedures is equivalent to the sit without moving term, the range may change to be inaccessible rapidly from the sit still state, to a great extent restricting the sum of information to be traded.

Because of the way of irregular network in ICMCRNs, a characteristic approach to manage the steering issue is to receive the versatility helped directing strategy, i.e., store carry- forward. In any case, straightforwardly applying the conventional versatility helped steering components for ICMCRNs may prompt wasteful steering execution due to the disgraceful basis for selecting transfers. A decent transfer in customary portability helped steering that lone considers the opportunity to get in touch withwith the goal may not be a decent in ICMCRNs on the grounds that if range band does not exists amid their contact, the contact gets to be worthless. Indisputably, for ICMCRNs, none of the customary CRN steering calculations are fitting because of the supposition of the presence of stable end-to-end ways nor the conventional versatility helped steering calculations are appropriate since they just consider worldly and spatial spaces while the steering productivity of ICMCRNs too relies on upon the range space. [1-10]

To deal with the steering test of ICMCRNs, a Mobility-Assisted Directing calculation with Spectrum Awareness (MARSA) is proposed in this paper, which chooses transfers by considering not just the chance that a hub meets the goal additionally the chance at which there exists no less than one accessible channel when they meet. At the end of the day, MARSA considers the data from the transient, spatial, and range areas for directing way development. To the best of our insight, this paper is the first to present the possibility of portability helped steering to ICMCRNs to manage the irregularly associated property, and the in the first place to upgrade the versatility helped steering with range attention to adjust the directing test.[11] 


\section{DESIGN MOTIVATION}

In this segment, we exhibit the portability attributes of the hubs also, the range abused by MARSA, which are acquired by breaking down this present reality marvel and follow information.

\section{NODE MOBILITY}

In true, the versatility of hubs, (for example, people alternately vehicles) is generally exceptionally energetic. Busses what's more, planes touch base in specific spots at specific times under typical conditions. Consequently, the versatility of hubs displays spatial and fleeting normality. This quality is confirmed by the information got through following the directions of 100,000 unknown cell phone clients for a 6 months time frame, in which the hubs are found in their initial two favored spots with a likelihood more than $40 \%$. A 3 months record catching the versatility examples of 50,000 hubs picked from around 10 million unknown cell phone clients likewise exhibits that individuals more often than not stay in their exceptionally went by spots at a hourly consistency. [12]

\section{A. Spectrum Mobility Shows Regularity}

Numerous certifiable datasets show that the exercises of PUs are not irregular. For instance, the dataset ] in view of the charging data of one European cell phone administrator shows the change of patterns of normal number of calls per hour and the normal call for every weekday in a week are fundamentally the same as. The roughly normal practices leads to the inexact consistency of the portability of the range that can be accessed for SUs. The portability normality of the hubs mixes us to plan an ICMCRN directing system also, a hand-off choice calculation, which will be displayed in the following two segments. [13]

\section{THE FRAMEWORK FOR MARSA}

In light of the perceptions from this present reality information, the regularities of the hubs and the range are firmly identified with the spots individuals visit.

Definition 4.1 (Home). The home of a hub j, signified by $\mathrm{Hj}$, is an arrangement of zones it typically visits.

There are two straightforward procedures for deciding the home of a hub: 1) a hub can arrange the zones it typically reaches as if it is its home; and/or 2) it can powerfully include a zone to its home once the meeting recurrence of the zone is bigger than a given limit. Correspondingly, either statically or powerfully a zone can be erased from a hub's home.

Neighbor Set: The neighbor set of hub $\mathrm{j}$, indicated by $\mathrm{Nj}$, is an arrangement of hubs so as to can convey straightforwardly with $\mathrm{j}$ if there exists no less than one accessible channel. Any two hubs situated at similar zone can discuss specifically with each other if no less than one channel is accessible. In view of this presumption, every one of the hubs secured by the zone where $\mathrm{j}$ lives have a place with $\mathrm{Nj}$. More by and large, $\mathrm{Nj}$ incorporates the hubs in a neighboring zone that can speak with $\mathrm{j}$ straightforwardly if range is accessible. Destination Zone: The zone the goal d as of now dwells is the goal zone, indicated by $\mathrm{Zd}$.

Spectrum Availability: The range accessibility is the likelihood that there exists more than an accessible channel to convey. [14]
InMARSA, the ideal opportunity for every zone is partitioned into equivalent length cycles. Inside every cycle, it is additionally partitioned into rise to length interims. An interim's length relies on upon the variety of the accessible range: if it is huge, it ought to be lessened; else, it ought to be extended. Because of the day by day standard practices of individuals, a hub should occasionally show up in its home zones at settled interval(s) amid every cycle.

Highly Available Visit: A exceptionally available visit is the range accessibility is greaterr than a given limit Th.

Two hubs trade their directing data at whatever point they contact is required. The data conveyed by every hub $\mathrm{i}$ is spoken to as three-tuples $\mathrm{fZj}$; Ti j; Pi j g, with one for every home zone, where $\mathrm{Zj} 2 \mathrm{Hi}$, Ti j $1 / 4 \mathrm{fti} \mathrm{j} 1$; ti $\mathrm{j} 2$; . . g is the arrangement of beginning time at which i generally visits $\mathrm{Zj}$, and $\mathrm{Pi} \mathrm{j} 1 / 4$ fpi $\mathrm{j} 1$; pi j2; . . g, with every pi jk speaking to the range accessibility in the meeting interim beginning from ti $\mathrm{jk}$.

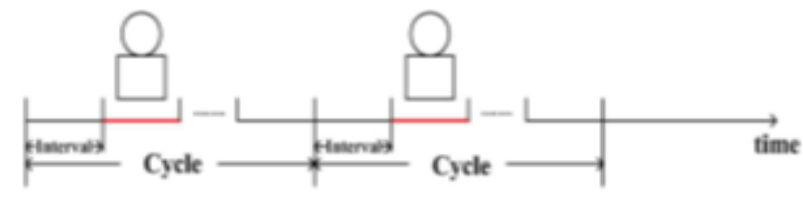

Fig.1 Node appears home zones each cycle.

Since the range portability is standard in all actuality the range accessibility in every zone of every interim can be derived by investigating the long haul measurable information. It isnecessities to think the distribution of the range amongst various SUs: the manyof theSUs viewing for the same channel, the lower the range accessibility. Thus the strategy for sending the halfway looked after database to get accessible channel data is broadly utilized as a part of CRNs.

\section{DESCRIPTION OF MARSA}

This area points of interest the MARSA calculation. Its code is given in Algorithm. Since every hub has capacity, any hub $\mathrm{j}$ at present holding the information detects the range occasionally, as proposed by In the event that no less than other channel is accessible, hub $\mathrm{j}$ needs to upgrade its neighbor set $\mathrm{Nj}$.

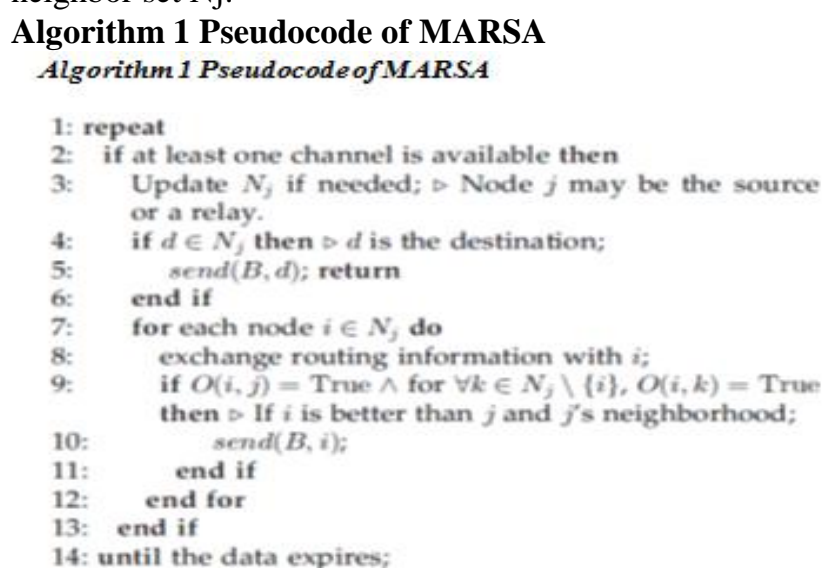




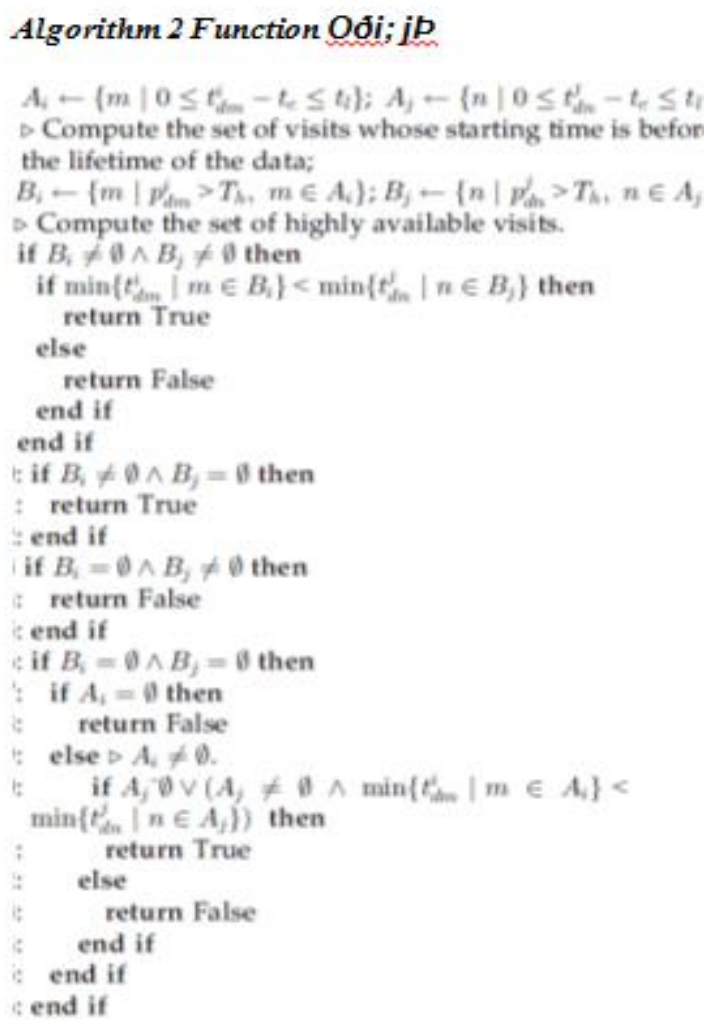

\section{Algorithm 2 Function Oði; jP}

The capacity judges if hub $i$ is further ideal than $j$ to go about as a transfer. In the event that it is yes, then it returns True; or generally False. Thus the procedure of Function is given in the above Algorithm , where tc is the present time whereastl is the rest of the lifetime of the information. For 2 hubs in which both having no less than one profoundly accessible reaches to $\mathrm{Zd}$, or both just having no less than one stay as opposed to the exceedingly accessible oneto $\mathrm{Zd}$, if the most punctual visit of one hub is earlier than the other, which is more ideal .

\section{NUMERICAL VALIDATION}

To approve the hypothetical examination, we build a recreated organize which contains 10 zones. Every zone at every interim may have expresses: a sit out of gear state what's more, a bustling state. We arbitrarily appoint the sit still and occupied various at various intervals. Worldly and land varieties the alloted spectrumrange from $15 \%$ to $85 \%$. Thus we set the range accessibility to be an irregular number running from $15 \%$ to $30 \%$ for the bustling state. If an information could be conveyed effectively in a zone amid an interim relies on upon the range accessibility at that zone amid that interim. $\mathrm{Th}=0: 5$ in this reproduction.

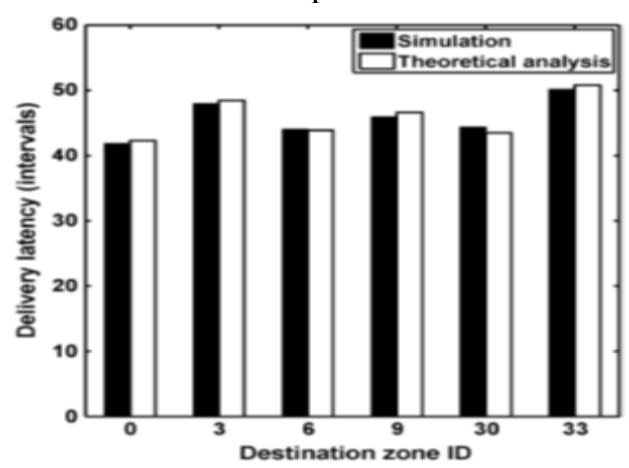

Fig.2: Validating the average delivery latency
There are 200mobile hubs and 100 stationary hubs. Every versatile hub moves in light of the time-variation group portability (TVCM) display, where every hub is haphazardly dispensed some home zones as its group and 24 interims periods, to be specific 24 hours. On the off chance that a hub should interim, it has a bigger likelihood to visit the coveted zone.Anodemoves as indicated by the arbitrary bearing portability demonstrate inside a zone. We select every single portable hub stationary hubs as goals living at the first, fourth, seventh, and tenth lines and sections of the 10 framework organize. We test the conveyance proportion, conveyance inertness of every correspondence combine. Every analysis is rehashed 50 times various arbitrary seeds for factual certainty. The normal rate at which every hub contacts with others is set by factual estimations of the recreation. In our hypothetical examination, for every goal, we decide the sort of the hubs toward the start of the entire reproduction to get and that toward the start of every interim to get the state move network, lastly to compute the normal conveyance proportion and latency.1 [15-20]

\section{PERFORMANCE ANALYSIS}

Here, the execution of MARSA IS accessed. For this reason we build up a remain solitary, occasion test system utilizing both this present reality information and the engineered information as the sources of info. Thus in this paper, we just look at our steering plan with its rearranged renditions and a few customary portability helped directing calculations, which are all presented in the accompanying:

\section{B.The Epidemic Algorithm}

In the plague calculation, a hub duplicates the information to each recently experienced hub that does the information $s$ an accessible channel.

\section{C.The Basic Algorithm}

In the essential calculation, finds a neighboring hub ideal as well as its different neighbors, it exchanges the information to that neighbor. At that point the information won't be conveyed to whatever other hub with the exception of the goal. At the end of the day, the fundamental calculation is a solitary duplicate single-hand-off rendition of MARSA.

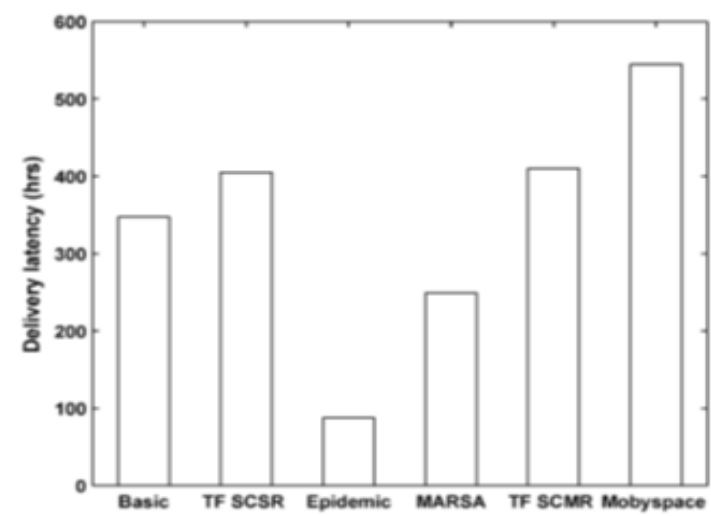

Fig3. Delivery latency comparison 


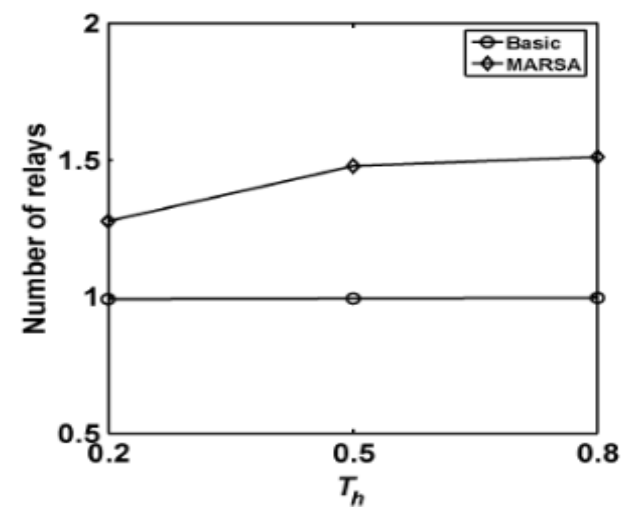

Fig4. Impact of Th on the number of relays.

\section{CONCLUSION}

This presentation brings the possibility of assisted mobility directing to portable impromptu CRNs. The future directing calculation called MARSA will not considers the possibility that a hub meets the goal, yet additionally the possibility of fruitful interchanges when two hubs meet. Thus a point by point examination onMARSA and utilize reenactment study to approve our examination is made. The execution of MARSA is additionally assessed in light of both genuine follow information and engineered information. By contrasting with best in class portability based calculations, we watch that MARSA obviously performs well as far as conveyance dormancy and conveyance proportion. In our future research, we will mutually consider transfer determination and range administration (range detecting, sharing, and versatility) for ICMCRNs as impedance affects the viability of transfer choice

\section{REFERENCES}

1. Kongkham, D. \& Sundararajan, M. 2019, "Distributed wideband sensing method for faded dynamic spectrum access", International Journal of Innovative Technology and Exploring Engineering, vol. 8, no. 10, pp. 4309-4312.

2. Balaji, S., John Paul Praveen, A. \& Mohanraj, R. 2019, "Recognizable proof and analysis of palm print in biometric authentication system using bayes techniques", International Journal of Innovative Technology and Exploring Engineering, vol. 8, no. 9 Special Issue 3, pp. 1126-1129.

3. Kavitha, G., Priya, N., Velvizhi, R. \& Allin Geo, A.V. 2019, "Parallel computation in correspondence and signal processing", International Journal of Innovative Technology and Exploring Engineering, vol. 8, no. 9 Special Issue 3, pp. 1136-1139.

4. Hema, R., Sundararajan, M. \& Balaji, S. 2019, "Smartphone control robot with automatic firing gun", International Journal of Innovative Technology and Exploring Engineering, vol. 8, no. 9 Special Issue 3, pp. 625-627.

5. Kaliyamurthie, K.P., Sundar Raj, B., Velvizhi, R. \& Shanmugapriya, K. 2019, "Dual band paper substrate CPW antenna for wireless applications", International Journal of Innovative Technology and Exploring Engineering, vol. 8, no. 9 Special Issue 3, pp. 605-608.

6. Geo, A.V.A., Arunachalam, A.R., Michael, G. \& Elankavi, R. 2019 "Evaluating architecture using compact modalities", International Journal of Innovative Technology and Exploring Engineering, vol. 8, no. 9 Special Issue 3, pp. 836-838.

7. Theivasigamani, S., Jeyapriya, D. \& Anita Davamani, K. 2019, "Anamoly analyzing and exploring for wireless sensor networks", International Journal of Innovative Technology and Exploring Engineering, vol. 8, no. 9 Special Issue 3, pp. 1116-1118.

8. Jeyapriya, D., Theivasigamani, S., Velvizhi, R. \& Nandhini, P. 2019, "Program detection in wireless feeler networks", International Journal of Innovative Technology and Exploring Engineering, vol. 8, no. 9 Special Issue 3, pp. 1194-1195.

9. Gowri Sankaran, B., Karthik, B. \& Vijayaragavan, S.P. 2019, "Image compression utilizing wavelet transform", International Journal of
Innovative Technology and Exploring Engineering, vol. 8, no. 10, pp. 4305-4308

10. Gowri Sankaran, B., Karthik, B. \& Vijayaragavan, S.P. 2019, "Weight ward change region plummeting change for square based image huffman coding", International Journal of Innovative Technology and Exploring Engineering, vol. 8, no. 10, pp. 4313-4316.

11. Hema, R., Sundararajan, M. \& Balaji, S. 2019, "Smartphone control robot with automatic firing gun", International Journal of Innovative Technology and Exploring Engineering, vol. 8, no. 9 Special Issue 3, pp. 625-627.

12. Rangaswamy, K. \& Rajabhushanam, C. 2019, "Congestion control in wireless network using TCP friendly rate control (TFRC)", International Journal of Recent Technology and Engineering, vol. 8, no. 2 Special issue 3, pp. 1598-1602

13. Tamil Selvan, S. \& Sundararajan, M. 2019, "Performance Parameters of 3 Value 8t Cntfet Based Sram Cell Design Using H-Spice", International Journal of Recent Technology and Engineering, vol. 8, no. 2 Special issue 5, pp. 22-27.

14. Vinoth, V.V. \& Kanniga, E. 2019, "Steganographical techniques in hiding text images - system", International Journal of Recent Technology and Engineering, vol. 8, no. 2, pp. 6535-6537.

15. Saravana, S., Balaji, S., Arulselvi, S. \& John Paul Praveen, A. 2019, "Reliable power quality monitoring and protection system", International Journal of Innovative Technology and Exploring Engineering, vol. 8, no. 9 Special Issue 3, pp. 644-645.

16. Sundaramoorthy, A. \& John Wiselin, M.C. 2019, "Single patch antenna with multiple feed", International Journal of Innovative Technology and Exploring Engineering, vol. 8, no. 9, pp. 1743-1747.

17. Velavan, R., Bharanidharan, S. \& Sheeba, B. 2019, "EMF pollution Causes, effects and protection", International Journal of Innovative Technology and Exploring Engineering, vol. 8, no. 9 Special Issue 3, pp. 1166-1168.

18. Veer, R.A., Arulselvi, S. \& Karthik, B. 2019, "Construction of ensemble square classification approaches in MIMO OFDM", International Journal of Engineering and Advanced Technology, vol. 8, no. 5, pp. 2039-2041.

19. Agitha, W. \& Kaliyamurthie, K.P. 2019, "Improved energy efficient in WBAN using MAC with cloud computing", International Journal of Innovative Technology and Exploring Engineering, vol. 8, no. 8, pp. 2405-2408.

20. Kastro, G.G. \& Wiselin, M.C.J. 2019, "Design and analysis of stub loaded resonator", International Journal of Recent Technology and Engineering, vol. 8, no. 1 Special Issue4, pp. 272-283.

\section{AUTHORS PROFILE}

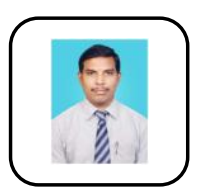

Karthik.B Assistant Professor, Department of Electronics And Communication Engineering,, Bharath Institute of Higher Education and Research, Chennai, India.

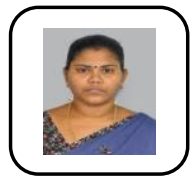

MeenaKumari.G Assistant Professor, Department of Electronics And Communication Engineering,, Bharath Institute of Higher Education and Research, Chennai, India

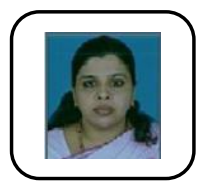

Jasmin.M, Assistant Professor, Department of Electronics And Communication Engineering,, Bharath Institute of Higher Education and Research, Chennai, India 